\title{
Dynamic penetration test with measuring of the pull-out resistance
}

\author{
Shun-ichi Sawada \\ Chie Engineer, Engineering Headquarters, OYO Corporation, 2-61-5, Toro, Kita-ward, Saitama, SAITAMA, 331-8688, JAPAN
}

\begin{abstract}
The cone penetration test is one of the most important and convenient tools for soil investigations. In recent decades, many efforts have been made to extend its applications to various fields in geotechnical engineering. This paper presents a newly developed dynamic cone penetration test with measuring of the pull-out resistance, which is named "Penetration \& Pull-out Test (PPT)". PPT consists of the dynamic penetration test and the quasi-static pull-out resistance test. " $N$-value", the number of blows for penetration into soil under the undrained condition is measured from the dynamic penetration test, while the friction resistance of soil under the drained condition is measured from the quasi-static pull-out test. The validation test results indicate that PPT is highly useful for mitigation of liquefactioninduced problems due to earthquakes. PPT is a break-proof device because it is equipped without electrical sensor at the tip of the cone. As the future direction of this study, we will develop a more economical and simpler in-situ apparatus for judging the liquefaction susceptibility of soils.
\end{abstract}

Keyword: sounding, dynamic penetration test, soil classification

\section{INTRODUCTION}

Many case histories on earthquake disasters have been showing that significant damages occurred in soft grounds around the coastal urban areas in Japan due to the soil liquefaction. At present, the liquefaction potential can be evaluated only at limited points because the estimation of liquefaction susceptibility requires detailed data from the cyclic loading test with undisturbed samples in laboratory.

In particular, the liquefaction susceptibility in an area is judged based on sparse data. Past investigations on earthquake damages indicate, on the other hand, that degree of damage often varies significantly even in a small area. Therefore, a more precise evaluation is required for the reliable design against soil liquefaction. It seems very difficult to carry out more conventional tests because of significant increase in the investigation cost. Some cost-effective method is required from the engineering point.

The past studies on soil liquefaction problems have mainly focused on the liquefaction resistance from the laboratory tests, while studies on in-situ estimation of the liquefaction potential have been relatively poor.

We estimated the liquefaction susceptibility using the dynamic penetration with measurement of the pull-out resistance. A piece of special equipment by which the resistance can be measured continuously during pull-out was developed. Then new indices were proposed to estimate the soil classification and the liquefaction susceptibility of soils.

\section{TEST EQUIPMENT AND PROCEDURES}

Fig. 1 shows a schematic figure of the dynamic penetration test with measurement of the pull-out resistance which is named "Penetration \& Pull-out Test (PPT)" proposed in this paper. This system consists of the dynamic penetration test and the pull-out resistance test.

A light-weight dynamic penetration device which is named "Mini Ram Sounding (MRS)" modified from the Swedish Ram Sounding test equipment was used.

The MRS system can be easily brought into fields without a truck vehicle and can be set up within 5 minutes. The dynamic penetration can be automatically driven by an electric motor. Fig. 2 shows the view of PPT-system during the dynamic penetration test in the field. And Fig. 3 shows the cone tip.

This equipment is modified by Piezo Drive Cone ${ }^{2,3), 4), 5)}$. Displacement sensor, trigger, handy teminal and data logger system are diverted with Piezo Drive Cone system.

A view of the newly developed pull-out equipment is shown in Fig. 4. The pull-out resistance is measured between the center rod clamp and two hydraulic cylinders. Two sets of load cells correct the eccentric loading through bridge circuits. Because any impact load does not arise during the quasi static pull-out operation, high-precision static strain gauges are used for the load cells. The up-and-down motion of the hydraulic cylinders changes to the opposite direction when reaching a constant length. When the hydraulic cylinders 


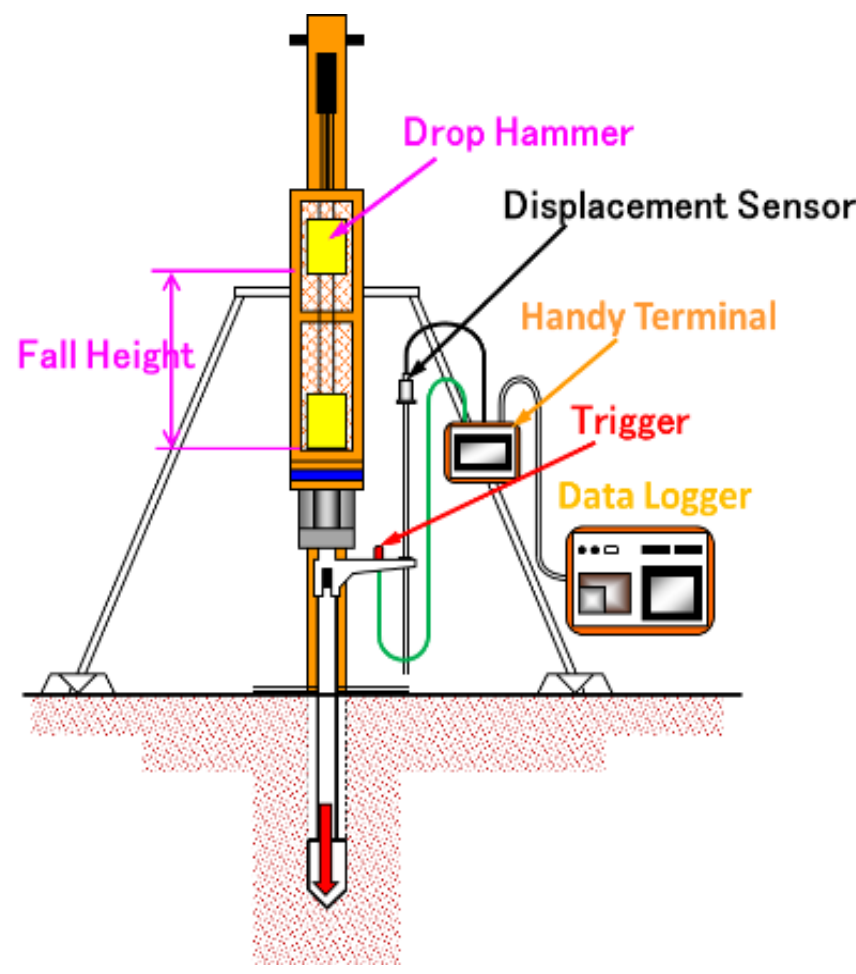

(a) Dynamic Penetration Test

Fig 1. Penetration \& Pull-out Test (PPT)

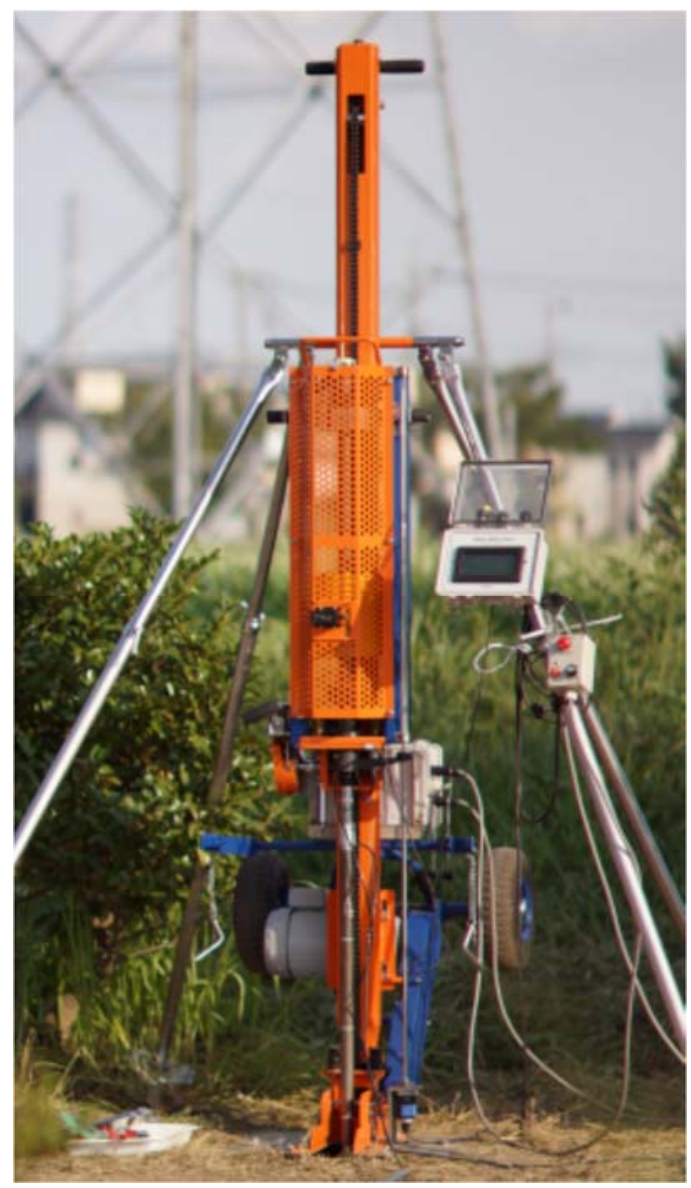

Fig. 2. View of Penetration \& Pull out Test (PPT) during dynamic penetration

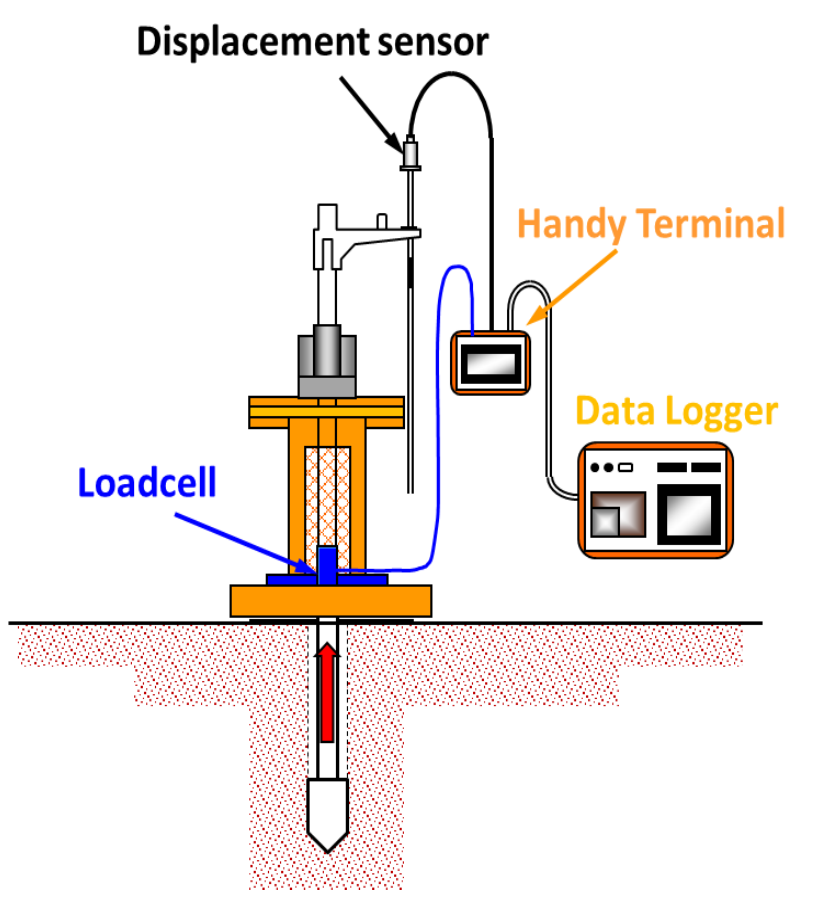

(b) Quasi-static Pull out Test

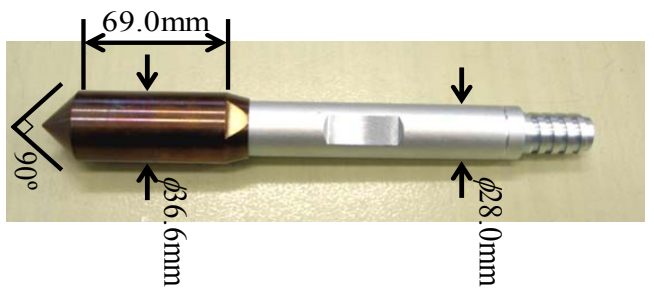

Fig. 3. View of Cone tip

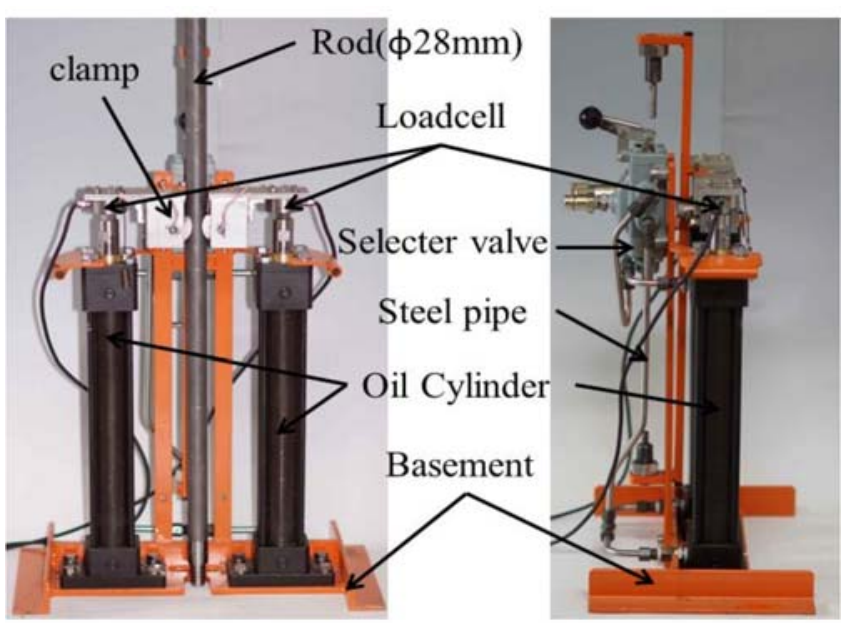

(a)Front View

(b)Side View

Fig. 4. New developed pull out equipment

are extending, the pull-out resistance is measured.

Furthermore, the lengths of two hydraulic line routes are equal so that the oil pressure in the cylinder of right side and left side are equal. 


\section{DATA PROCESSING}

The flow chart for data processing to evaluate the liquefaction susceptibility by PPT-method is shown in Fig. 5. All data except the unit weight can be obtained by PPT consisting of the dynamic penetration test and the pull-out resistance test by the quasi-static pull-out operation. The unit weight is not a sensitive quantity for evaluating the liquefaction susceptibility.
Fig. 6(c) illustrates the pull-out resistance profile of the specially modified PPT, in which the load cell is mounted at the cone tip after the dynamic penetration. The modified PPT can take into account locally lower pull-out resistance in the sandy soil layer rather than in the clay layer during quasi-static pull-out operation.

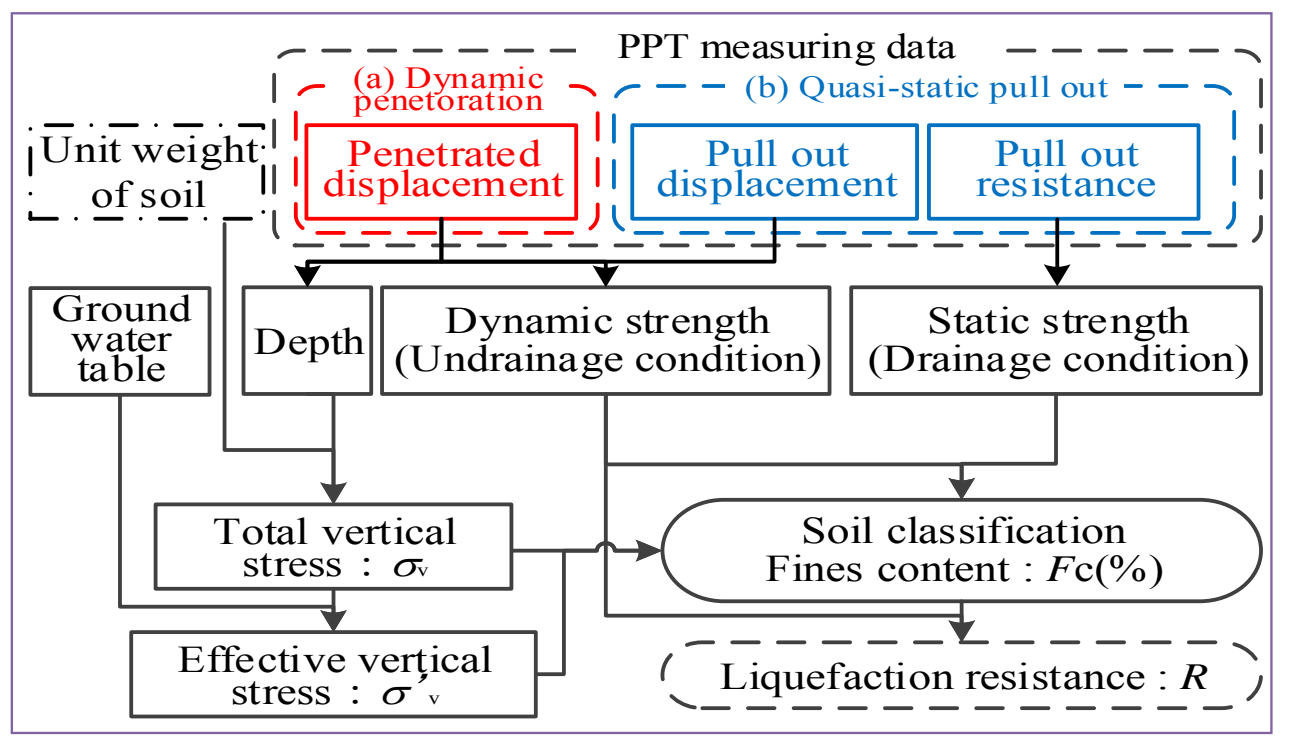

Fig. 4. Flowchart of evaluating liquefaction strength using PPT

\section{TEST SITE CONDITIONS \& EXAMPLE DATA BY PPT}

The test site is located in the Kanto plains area along The Tone River, Japan. The soil profile, SPT $N$-values and fine content values of soils from the laboratory test are shown in Fig. 6.

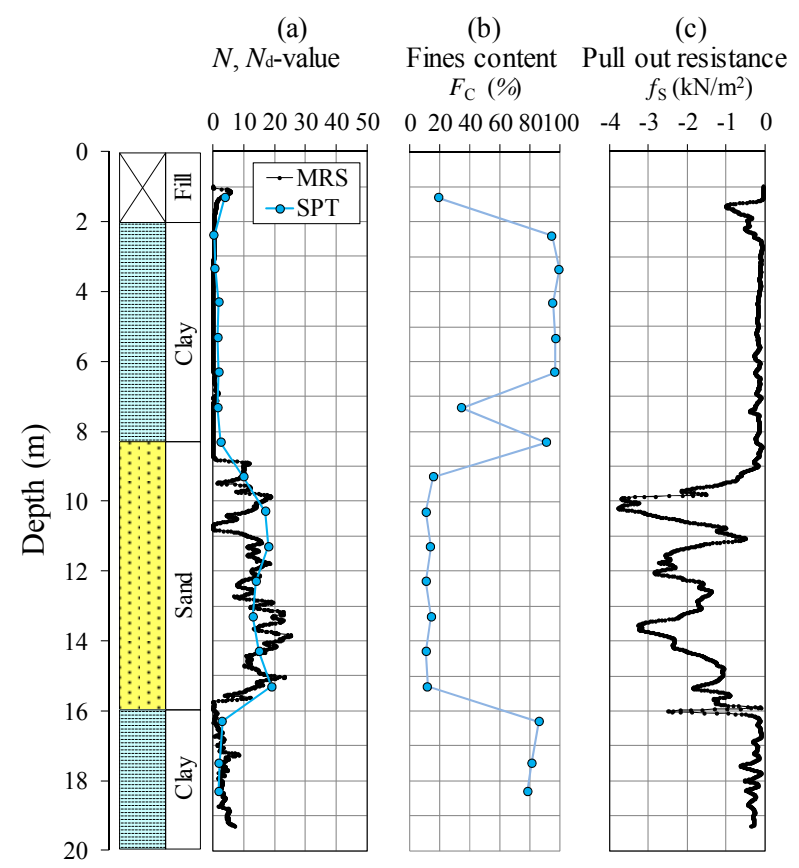

Fig. 6. Soil profile by SPT and pull-out resistance

\section{CAPABILLITY OF SOIL CLASSIFICATION USING PPT}

Wroth $^{6}$ suggested that CPT data should be normalized using the following parameters:

Normalized penetrated cone resistance $\left(Q_{t}\right)$ and normalized pull-out resistance $\left(F_{t}\right)$ can be calculated from the following equation:

$$
\begin{aligned}
& Q_{t}=\frac{q_{t}+\sigma_{v 0}}{\sigma_{v 0}^{\prime}} \\
& F_{t}=\frac{f_{s}}{q_{t}-\sigma_{v 0}} \times 100
\end{aligned}
$$

where $q_{\mathrm{t}}=$ cone resistance corrected for the unequal end area effect, $q_{\mathrm{t}}=392 \times N_{\mathrm{d}}\left(\mathrm{kN} / \mathrm{m}^{2}\right)$

$f_{\mathrm{s}}=$ pull-out resistance at the cone tip $\left(\mathrm{kN} / \mathrm{m}^{2}\right)$

$\sigma_{\mathrm{v} 0}=$ total vertical stress $\left(\mathrm{kN} / \mathrm{m}^{2}\right)$

$\sigma_{\mathrm{v} 0}^{\prime}=$ effective vertical stress, $\sigma_{\mathrm{v} 0}-u_{0}\left(\mathrm{kN} / \mathrm{m}^{2}\right)$ 

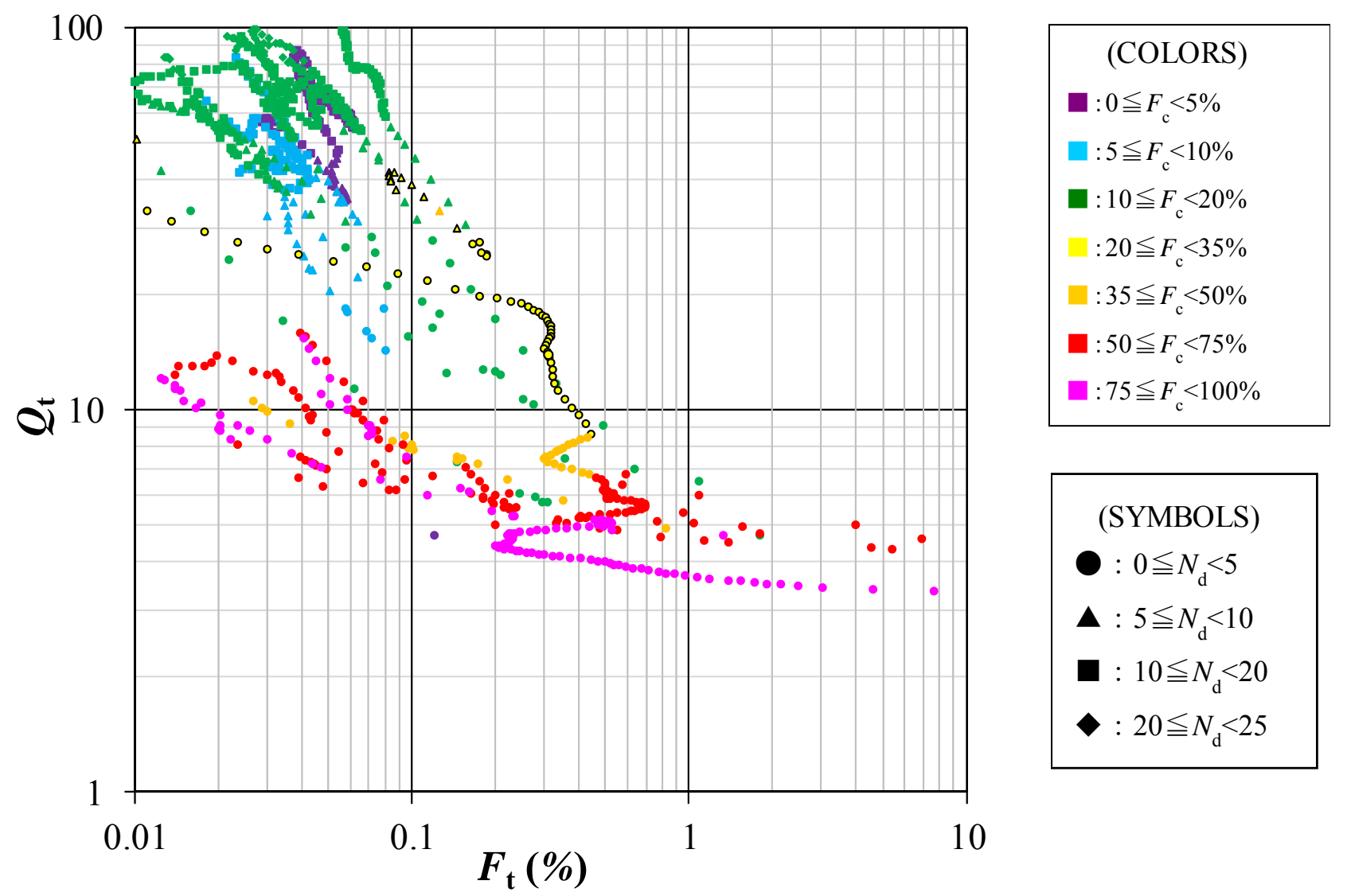

Fig. 6. Example for soil classification chart based on PPT

Based on these normalized parameters and by using the extensive CPT database now available in published and unpublished sources, the modified soil behavior type classification charts have been proposed by Robertson ${ }^{1)}$.

Fig. 6 shows the example chart for soil classification between normalized penetrated cone resistance $\left(Q_{t}\right)$ and normalized pull-out resistance $\left(F_{t}\right)$ based on PPT data.

Color scales of the legend show the range of fine contents. The warm color scale, for instance from red to yellow color indicate the high fine contents that is clayey soil, and the cold color gray scale, for instance from green to dark blue color indicate the low fine contents that is sandy soil. The distribution of the relationship between normalized penetrated cone resistance $\left(Q_{t}\right)$ and normalized pull-out resistance $\left(F_{\mathrm{t}}\right)$ based on PPT data shows that these data can be used for the soil classification.

\section{CONCLUSION REMARKS}

The following conclusions were obtained from a series of dynamic penetration and quasi-static pull-out resistance test results.

(a) The distributions of the converted $N_{\mathrm{d}}$-values by a single blow can be used to identify the uniformity of layer and to find inter-bedded layer. (b) The distribution of the relationship between normalized penetrates cone resistance $\left(Q_{t}\right)$ and normalized pull out resistance $(\mathrm{Ft})$ based on PPT data shows that these data can be used for the soil classification.

\section{REFERENCES}

1) Robertson, P.K. (1990). Soil classification using the cone penetration test. Canadian Geotechnical Journal, 27(1), 151158.

2) Sawada, S. (2004), Estimation of liquefaction potential using dynamic penetration with pore pressure transducer, International Conference on Cyclic Behavior of Soils and Liquefaction Phenomena, Bochum, pp. 305-312.

3) Sawada, S., Tsukamoto, Y. \& Ishihara, K., (2005), Method of dynamic penetration with pore pressure transducer. Part 6 Liquefaction resistance, Proc. Geotechnical engineering symposium, pp.1-6(in Japanese).

4) Sawada, S., (2009), Evaluation of strength of soils against liquefaction using Piezo Drive Cone, 4th International Conference on Earthquake Geotechnical Engineering, PaperNo.1146, 2007.

5) Sawada, S., (2009), Evaluation of differential settlement following liquefaction using. Piezo Drive Cone, 17th International Conference on Geotechnical Engineering, Alexandria, Egypt, pp. 1064-1067.

6) Wroth, C. P. (1984). The interpretation of in situ soil test. 24th Rankine Lecture, Geotecnique, 34(4), pp. 449-489. 